\title{
Sastra Hijau: Pendidikan Lingkungan dalam Novel Klasik
}

\author{
Onok Yayang Pamungkas \\ Universitas Ma'arif Nahdlatul Ulama Kebumen \\ onokyayangpamungkas@gmail.com
}

\begin{abstract}
Abstrak
Penelitian ini merupakan upaya untuk mengeksplanasi nilai pendidikan lingkungan dalam Quadriologi Novel Karya Ki Padmasusastra (selanjutnya disebut QNKKP) dalam perspektif budaya Jawa. Penelitian ini menggunakan paradigma penelitian kualitatif. Objek penelitian ini disebut cyber sastra, karena data diambil dari situs online. Data utama penelitian adalah empat novel karya Ki Padmasusastra. Teknis analisis data menggunakan teknik analisis isi melalui sudut pandang hermeneutika budaya. Hasil penelitian menunjukkan bahwa, QNKKP merupakan sastra Jawa kontemporer yang menggambarkan kondisi sosiokultural Jawa pada tahun 1901 s.d. 1924, yang kuat dengan nilai etis lingkungan. Nilai kearifan lingkungan Jawa merupakan kombinasi dari budaya leluhur dan kepercayaan Hindu. Praktik lingkungan manusia Jawa menjunjung harmonisasi, empati, rasa hormat, dan saling membutuhkan terhadap makhluk non-manusia. Sikap pro-lingkungan yang melekat dalam QNKKP dapat memainkan peran penting dalam memupuk rasa tanggung jawab manusia terhadap lingkungan. Signifikansi narasi ekologi dan etika lingkungan dalam QNKKP memberikan kontribusi terhadap reorientasi beberapa pandangan tentang praktik lingkungan tradisional di negara-negara berkembang. Implikasi penting dari temuan penelitian adalah kesadaran manusia untuk saling menghormati sesama entitas yang ada akan dapat membangun kekuatan yang dapat membimbing manusia agar etis terhadap semua unsur kehidupan. Melalui pembacaan instrinsiknya, nilai-nilai pendidikan pada QNKKP dapat dijadikan plaform pada pendidikan etis lingkungan. Untuk itu, QNKKP terlibat dalam ekologi melalui tiga cara, yakni pendidikan lingkungan, intelektual ilmiah, dan praktis.
\end{abstract}

Kata Kunci: Kearifan Lingkungan; Nilai Pendidikan; Ekologi Sastra

\begin{abstract}
This research is an attempt to explain the value of environmental education in the Quadriology Novel by Ki Padmasusastra (hereinafter referred to as QNKKP) in the perspective of Javanese culture. This study uses a qualitative research paradigm. The object of this research is called cyber literature, because the data is taken from online sites. The main data of this research are four novels by Ki Padmasusastra. Technical analysis of data using content analysis techniques from the point of view of cultural hermeneutics. The results showed that, QNKKP is a contemporary Javanese literature that describes the socio-cultural conditions of Java in 1901 s.d. 1924, which is strong with environmental ethical values. The value of Javanese environmental wisdom is a combination of ancestral culture and Hindu beliefs. Javanese human environmental practices uphold harmonization,
\end{abstract}


empathy, respect, and mutual need for non-human beings. The pro-environmental attitude inherent in QNKKP can play an important role in fostering a sense of human responsibility towards the environment. The significance of ecological narratives and environmental ethics in the QNKKP contributes to the reorientation of some views on traditional environmental practices in developing countries. An important implication of the research findings is that human awareness to respect each other's existing entities will be able to build strength that can guide humans to be ethical towards all elements of life. Through its intrinsic reading, the educational values at QNKKP can be used as a platform for environmental ethical education. For this reason, QNKKP is involved in ecology in three ways, namely environmental education, intellectual science, and practicality.

Keywords: Environmental Wisdom; Educational Value; Literary Ecology

\section{Pendahuluan}

Nasib bumi sekarang ini memang sudah mencapai situasi yang sangat mengerikan. Masalah ini setidaknya dilatarbelakangi oleh revolusi ilmiah dan industri yang diaktifkan oleh negara-negara kapitalis Barat, yang terus mendominasi aspek budaya, politik, dan lingkungan. Dalam 300 tahun terakhir, industri terus mendominasibumi danmengontaminasi alam (Beattie \& Liu, 2016; York \& Rosa, 2003; Gaard, 2001), dengan hanya memberikan kepentingan komersial (Hooti \& Ashrafian, 2014; Nichols, 2011). Dampaknya adalah kerusakan lingkungan yang berakibat pada peningkatan risiko bencana global.

Sejumlah strategi beberapa tahun terakhir terus diusulkan untuk menangani masalah lingkungan; seperti mengembangkan teknik tiruan alam (Habibi \& Karbalaei, 2015); pengembangan konservasi manajemen pengolahan lingkungan (Asteria et al., 2016; Capano et al., 2019; Paterson, 2006; McDonald, 2015). Dalam ranah pendidikan, berbagai perubahan kurikulum pembelajaran yang menekankan kontribusi pada wacana lingkungan juga telah dicoba (Bishop et al., 2000; Dikicigil \& Gülersoy, 2020; Helvaci \& Helvaci, 2019; Kim, 2014); termasuk pendidikan lingkungan berbasis game online (Cheng et al., 2013). Ini karena pendidikan lingkungan (Suwandi et al., 2019) merupakan faktor penting untuk meminimalkan kerusakan lingkungan.

Banyak ide yang muncul dari berbagai perspektif untuk memikirkan kesadaran masyarakat terhadap lingkungan. Untuk permasalahan ini, cerita kreatif, karya sastra, dan kearifan tradisional bisa menjadi sumber penting untuk membangun kesadaran, (Barau, dkk., 2016), dan mengarahkan seseorang untuk peduli terhadap lingkungan (Mobley, Vagias, \& DeWard, 2009; Von Mossner, 2019). Karena di satu pihak, sastra seringkali memberikan pemahaman secara mendalam terkait dengan nilai-nilai lingkungan (Dewi, 2015; Odinye, 2018). Di lain pihak, sastra merupakan media pendidikan yang dianggap mempunyai kekuatan untuk membangun kesadaran dan membina sikap positif manusia tentang narasi besar penyelamatan lingkungan (Athanassakis, 2017; Gough \& Robottom, 1993; Pattaro, 2016; Thathong, 2012; Wiyatmi et al., 2016; Zhang et al., 2017). Dengan demikian, melalui nilai-nilai pada sastra, masyarakat (pembaca) diharapkan memiliki pengetahuan, sikap, motivasi, dan kesediaan untuk melakukan pemecahan dan pencegahan masalah lingkungan yang ada di sekitarnya.

Dalam banyak karya naratif Jawa, peneliti tertarik untuk mengeksplorasi nilai-nilai kultural tentang kearifan lingkungan dalam QNKKP. Karena, di satu pihak, QNKKP merupakan 
sastra yang memiliki kekuatan pada aspek kearifan lingkungn, baik filsafat maupun praktis. Di pihak lain, dari sisi pengarang, Ki Padmasusastra (pengarang) adalah sastrawan besar Jawa yang mendominasi seluruh masa peralihan ke zaman modern (Pamungkas et al., 2021; Wibowo, 2015). Ki Padmasusastra adalah bapak bahasa dan sastra Jawa abad ke-20 (Rass, 2014). Dia pelopor pembentukan novel Jawa modern (Quinn, 1982). Melalui QNKKP, Ki Padmasusastra dapat memberikan pembaca sebuah pendidikan tentang kesadaran ekologis dalam hubungan timbal balik antara manusia dan lingkungan.

\section{Metodologi Penelitian}

Penelitian ini adalah sebuah kajian interdisipliner tentang sastra, pendidikan lingkungan, filsafat, dan budaya. Untuk itu, Peneliti memilih untuk menggunakan paradigma penelitian kualitatif karena penelitian berupa fenomena yang belum terungkap dan tidak dapat diperoleh melalui prosedur statistik (bandingkan, Charmaz, 2011; Creswell, 2007; Sutopo, 2002; Strauss \&Corbin, 2010; Vanderstoep \& Johnston, 2008). Metode kualitatif cocok untuk mengungkap berbagai informasi kualitatif dalam teks sastra (Ratna, 2010), yang lebih menekankan pada asumsi, nilai, kepercayaan, dan ideologi individu peneliti (bandingkan, Charmaz, 2011).

Objek penelitian ini disebut sebagai cyber sastra karena data diambil secara online dalam situs https://www.sastra.org, yang dipublikasikan oleh Yayasan Sastra Lestari, Surakarta, Jawa Tengah, Indonesia. Sumber data penelitian adalah empat novel karya Ki Padmasusastra, yaitu Pethikan Saking Kabar Angin (1901), Serat Rangsang Tuban (1912), Serat Prabangkara (1921), Serat Kandha Bumi (1924). Data penelitian ini berupa teks (kata, frasa, dan kalimat) yang secara implisit maupun eksplisit mengandung aspek nilai-nilai pendidikan lingkungan. Data kualitatif diklasifikasikan melalui teknik analisis isi berdasarkan teks atau tema utama (Krippendorff, 1980).

Langkah-langkah analisis yang dilakukan meliputi: 1) pembacaan novel sekaligus pengumpulan data [teks] sesuai dengan kategori nilai-nilai pendidikan lingkungan; 2)mempelajaridan menganalisisdata dengan cermatsesuai dengan tujuan penelitian; 3) menginterpretasi dan memverifikasi data; 4) membuat kesimpulan; 5) dan setelah dibuat simpulan, peneliti melakukan pengecekan kembali untuk memastikan bahwa semua proses sudah sesuai dengan maksud dan tujuan penelitian.

\section{Hasil dan Pembahasan}

Penelitian ini dilakukan dengan sangat hati-hati melihat bentuk nilai-nilai pendidikan lingkungan dalam QNKKP. Berdasarkan analisis data yang dilakukan, ada beberapa hal yang dapat ditangkap. Hasil dan temuan penelitian akan diuraikan dalam bentuk deduktif, yakni bermula dari pemaparan temuan penelitian tentang representasi nilai pendidikan lingkungan; pembahasan teori dengan persepsi; lalu diakhiri dalam bentuk simpulan penelitian.

\subsection{Representasi Nilai Pendidikan Lingkungan}

Para ahli mengakui bahwa sastra memang dapat memberikan pendidikan lingkungan bagi pembaca (lihat, Buell, 2005; Dewi, 2018; Garrard, 2004; Glotfelty \& Fromm, 1996;(Pamungkas, 2021; Pamungkas et al., 2018) .Narasi dalam sastra diakui dapat memberikan banyak nilai-nilai pendidikan. Dalam QNKKP, pembaca diberikan banyak pembelajaran tentang kesadaran lingkungan. Berasarkan data, diperoleh 14 jenis pendidikan yang meliputi pendidikan 
moral, spiritual, estetika, konservasi alam, konservasi air, konservasi lahan kering, altruistik air, altruistik goa, altruistik tanaman, psikis, semiotika, kultural, filosofi, dan tradisi herbal. Dari 16 jenis pendidikan ini terkategori menjadi 29 bentuk pendidikan yang lebih spesifik. Paparan berdasarkan jenis pendidikan, bentuk pendidikan, kode data, judul, dan halaman novel diuraikan dalam tabel berikut.

Tabel 2. Bentuk dan jenis pendidikan lingkungan dalam QNKKP

\begin{tabular}{|c|c|c|c|c|}
\hline No. & $\begin{array}{l}\text { Jenis } \\
\text { Pendidikan }\end{array}$ & Bentuk Pendidikan & $\begin{array}{l}\text { Kode } \\
\text { data }\end{array}$ & Novel \& hlm \\
\hline \multirow{7}{*}{1.} & \multirow{7}{*}{ Moral } & menghormatialam, sungai, dan ikan & EE.01 & SKB/P.34-35 \\
\hline & & Menjaga keasrian sungai & EE.02 & SKB/P.40-41 \\
\hline & & Menjaga keasrian alam & EE.03 & SP/P.23 \\
\hline & & $\begin{array}{l}\text { Menyadarkan manusia tentang } \\
\text { manfaat air }\end{array}$ & EE.04 & SP/P.23-24 \\
\hline & & $\begin{array}{l}\text { Menumbuhkan sikap positif } \\
\text { terhadap lingkungan }\end{array}$ & EE.05 & SPSKA/P.237 \\
\hline & & Patuh kepada orang tua & EE.06 & SPSKA /P.313-314 \\
\hline & & $\begin{array}{l}\text { Menjaga kehidupan harmoni antara } \\
\text { manusia dengan lingkungan }\end{array}$ & EE.07 & SPSKA/P.27-28 \\
\hline \multirow{4}{*}{2.} & \multirow{4}{*}{ Spiritual } & Menyedekahkan hasil alam & EE.08 & SKB/P.3 \\
\hline & & $\begin{array}{l}\text { Percaya pada keberadaan alam } \\
\text { metaempiris }\end{array}$ & EE.09 & $\begin{array}{l}\text { SPSKA/P. 6-7; } \\
\text { P.85-89 }\end{array}$ \\
\hline & & $\begin{array}{l}\text { Menghargai nilai Gua sebagai } \\
\text { media spiritual }\end{array}$ & EE.10 & SPSKA/P.71-72 \\
\hline & & $\begin{array}{l}\text { Menghargai nilai alam sebagai } \\
\text { lokasi yang baik untuk bertapa }\end{array}$ & EE.11 & SP/P.95-96 \\
\hline \multirow[b]{3}{*}{3.} & \multirow[b]{3}{*}{ Estetika } & Menghargai nilai estetika alam & EE.12 & SP/P.23 \\
\hline & & Menghargai estetika goa & EE.13 & $\begin{array}{l}\text { SP/P.47-48, } \\
\text { SP/P.45-47 }\end{array}$ \\
\hline & & $\begin{array}{l}\text { Menghargai peran estetika alam } \\
\text { hubungannya dengan dampak } \\
\text { psikis manusia }\end{array}$ & EE.14 & SPSKA/P.92-93 \\
\hline
\end{tabular}

\begin{tabular}{cllll}
\hline & \multicolumn{2}{l}{ Cara menggarap sawah } & EE.15 & SPSKA/P.38 \\
\cline { 2 - 5 } $\begin{array}{c}\text { Konservasi } \\
\text { alam }\end{array}$ & $\begin{array}{l}\text { Membangun tempat tinggal dengan } \\
\text { ornamen alami }\end{array}$ & EE.16 & SPSKA /P.148-150 \\
\hline & Mengolah air sungai untuk & EE.17 & SP/P.61 \\
\hline
\end{tabular}




\begin{tabular}{|c|c|c|c|}
\hline \multirow[t]{2}{*}{5.} & \multirow{2}{*}{$\begin{array}{c}\text { Konservasi } \\
\text { air }\end{array}$} & \multicolumn{2}{|l|}{ pengairan tanaman dan masjid } \\
\hline & & $\begin{array}{l}\text { Mengolah air untuk pengairan } \\
\text { tanaman }\end{array}$ & SPSKA/P.39-40 \\
\hline 6. & $\begin{array}{l}\text { Konservasi } \\
\text { lahan kering }\end{array}$ & $\begin{array}{l}\text { Mengolah lahan kering menjadi EE.19 } \\
\text { lahan subur }\end{array}$ & SPSKA/P.214-217 \\
\hline \multirow[t]{2}{*}{7.} & Altruistik air & $\begin{array}{l}\text { Jasa alami air terhadap kehidupan EE. } 20 \\
\text { tanaman }\end{array}$ & $\begin{array}{l}\text { SP/P.23-24, } \\
\text { SP/P.59-60, } \\
\text { SP/P.77, }\end{array}$ \\
\hline & & $\begin{array}{l}\text { Jasa alami air terhadap kehidupan EE.21 } \\
\text { manusia }\end{array}$ & $\begin{array}{ll}\text { SPSKA/ } & \text { P.21-22, } \\
\text { P.71-72, } & \text { SKB/34- } \\
35 & \end{array}$ \\
\hline
\end{tabular}

\begin{tabular}{|c|c|c|c|c|}
\hline \multirow{2}{*}{8.} & \multirow{2}{*}{$\begin{array}{l}\text { Altruistik } \\
\text { Goa }\end{array}$} & $\begin{array}{l}\text { Jasa goa sebagai tempat tinggal } \\
\text { manusia }\end{array}$ & EE.22 & SP/P.35 \\
\hline & & Menghargai estetika alam & EE.23 & SPSKA/P.3 \\
\hline $\begin{array}{l}\text { A } \\
\text { tu }\end{array}$ & $\begin{array}{l}\text { Altruistik } \\
\text { tumbuhan }\end{array}$ & $\begin{array}{l}\text { Jasa tanaman untuk kehidupan } \\
\text { manusia }\end{array}$ & EE.24 & SRT/P.48-49 \\
\hline 10. & Psikis & $\begin{array}{l}\text { Keasrian alam dapat memberi } \\
\text { ketenangan psikis }\end{array}$ & EE.25 & $\begin{array}{l}\text { SP/P.23-24, } \\
\text { SP/P.21-22 }\end{array}$ \\
\hline 11. & Semiotika & $\begin{array}{l}\text { Menghargai hewan sebagai } \\
\text { lambang kekayaan }\end{array}$ & EE.26 & SKB/P.3 \\
\hline 12. & Kultural & $\begin{array}{l}\text { Menghargai hasil alam atas } \\
\text { manfaatnya padaperan kultural }\end{array}$ & EE.27 & SPSKA/P.8 \\
\hline 13. & Filsosofi & $\begin{array}{l}\text { Mendapat nilai pelajaran dari } \\
\text { kehidupan binatang }\end{array}$ & EE.28 & SP/P.23 \\
\hline 14. & $\begin{array}{l}\text { Tradisi } \\
\text { herbal }\end{array}$ & $\begin{array}{l}\text { Menghargai tanaman atas } \\
\text { manfaatnya sebagai obat tradisional }\end{array}$ & EE.29 & SKB/P.7-9 \\
\hline Keterangan: & $\mathrm{EE}$ & $=$ Environmental Education & & \\
\hline & $\mathrm{P}$ & $=$ Page & & \\
\hline & SKB & $=$ Serat Kandha Bumi & & \\
\hline & SPSKA & $=$ Serat Pethikan Saking Kabar Angin & & \\
\hline & SP & $=$ Serap Prabangkara & & \\
\hline & SRT & $=$ Serat Rangsang Tuban & & \\
\hline
\end{tabular}

Imajinasi lingkungan, sosial, tokoh, dan peristi wayang ada di dalam cerita QNKKP mewakili kondisi masyarakat pada zamannya. Imajinasi lingkungan yang di tampilkan dalam cerita merujuk pada pengalaman sosiokultural pengarang. Alur cerita dalam QNKKP menggambarkan situasi masyarakat yang masih sangat dekat dengan alam dan budaya tradisional. Hal ini tampak pada latar, perilaku tokoh, peristiwa, dan alur ceritanya. Kondisi ini 
dapat menjadikan wawasan pendidikan lingkungan yang positif bagi pembaca. Bentuk nilai pendidikan dalam QNKKP dipaparkan sebagai berikut.

\subsection{Pendidikan Moral}

Moral terhadap lingkungan merupakan cara pandang bahwa manusia mempunyai kewajiban etis untuk menghargai alam (Barau et al., 2016; Sukmawan, 2016). Bentuk ideologi moral terlihat, misalnya dalam Serat Kandha Bumi, yakni dalam pelarian Dewi Siti Pasir ketika meninggalkan kerajaan untuk mencari kakaknya, ia terhenti di sebuah sungai dengan suasana yang sangat asri. Meskipun dalam kondisi emosi yang sangat kalut, ia tetap bisa menahan emosinya. Bahkan, saat ia menceburkan kaki ke sungai, ia tidak marah ketika ikan-ikan kecil memakan kakinya.

"Dewi Siti Pasir perjalanannya tidak tentu arah, /.../ Perjalanannya berhenti di sebuah sendang yang sangat besar di tengahnya hutan /.../ Air sendang sangat jernih berlimpahlimpah, banyak ikannya wader berlalu lalang berdesakan bergerombol, ketiganya berderet-deret menempel di akar pohon beringin yang menjulur masuk di air /.../ Sang Dewi terkesan melihat, berhenti di pinggir kolam, duduk di batu, kaki dimasukkan ke dalam air seraya menggosok-gosok, daki dimakan oleh ikan wader secara berebutan, sebagian menggigit-gigit kuku hingga membuat geli” (Padmasusastra, 1924, P. 34-35).

Artinya, dalam kondisi apapun, tidak ada alasan bagi manusia untuk tidak menghormati alam. Meskipun inferior, alam tetap memiliki nilai pada dirinya sendiri, yang dalam kondisi tertentu, dan bahkan seringkali, membantu manusia untuk menjadi solusi masalah psikologi, seperti dalam kasus ini. Moral positif masyarakat Jawa memang didasarkan pandangan bahwa manusia dan alam adalah kesatuan eksistensi (Endraswara, 2016; Magnis-Suseno, 1984; Pamungkas et al., 2019). Karena itu, harus keduanya harus dijaga eksistensinya. Kesadaran tokoh dapat mendorong manusia untuk membentuk sistem moral ekologis (Barau et al., 2016; Pattaro, 2016). Kesadaran ini terkait dengan pemahaman masyarakat Jawa tentang alam semesta sebagai entitas yang memiliki nilai, sehingga layak untuk dihargai, dijaga, dan dirawat.

\subsection{Pendidikan Spiritual}

Mayarakat Jawa dalam QNKKP memiliki keyakinan spiritual yang kuat. Melalui sosok Ki Jaga Mandala yang memiliki kekayaan yang di sedekahkan kekayaannya kepada fakir miskin (EE.08, SKB/P.3) adalah fakta tentang keyakinan spiritual. Ini diyakini karena pengaruh kuat dari tradisi kepercayaan agama di Jawa tentang empati sosial. Masyarakat Jawa memiliki kepercayaan yang kuat tentang spiritualitas ekonomi untuk praktik sosial, demi terciptanya kehidupan yang hasmonis (Geertz, 1956; Tago, 2017). Kehidupan masyarakat dalam QNKKP tidak hanya dalam alam empiris, tetapi juga dalam alam metaempiris. Alam metaempiris tergambar melalui tokoh Prabu Bajrapati, yakni seorang yang telah meningal. Namun ia mempunyai peran dalam kehidupan manusia. Kutipan berikut menggambarkan hal tersebut.

"O cucuku tampan, kamu tidak boleh mempercepat waktu. Kamu sudah ditakdirkan oleh dewa akan menurunkan para ratudi Ngatasangin, sehingga kamu tidak akan hilang keturunanmu, lestari turun-temurun memegang kerajaan nagara Marutamanda dari turunmu, akan tetapi benihmu hanya tinggal satu serta yang kuat menjadi tempatnya juga hanya satu yaitu Dewi Angin-angin, anaknya Bagawan Anila dari pertapaan Sadaka" (SPSKA/P.6-7) 
Masyarakat dalam QNKKP sangat menghormati goa karena goa merupakan salah satu tempat yang memiliki nilai spiritual. Data EE.10, SPSKA/P.71-72 dan SP/P.95-96 memberi wawasan bagi kita tentang bentuk perilaku masyarakat Jawa yang menggunakan goa sebagai tempat untuk bertapa. Ini memang masih ada pengaruh dari kepercayaan Hindu-Budha (bandingkan, Magnis-Suseno, 1984; Sunyoto, 2012), dan juga pengaruh cerita wayang yang lama mengakar pada masyarakat Jawa. Untuk hal ini, wawasan spiritual tradisional Jawa ini nampaknya dapat membantu manusia untuk tetap mempertahankan alam.

\subsection{Pendidikan Estetika}

Latar dalam QNKKP memang banyak menceritakan kondisi alam Jawa pedesaan yang masih sangat asri. Tidak ada cerita tentang bentuk kejahatan manusia terhadap alam. Alur cerita tentang perjalanan Pangeran Prabangkara menuju perdesaan memberikan wawasan tentang keindahan panorama persawahan yang subur dan kehidupan binatang yang masih terjaga. Kondisi tergambar dalam kutipan berikut.

"kepergian sang pangeran dari kadipaten pada saat pagi hari. Perjalanannya tidak tentu arahnya, melewati persawahan dengan tanamannya yang menghijau, hijau terlihat dari jauh bergerak-gerak tertiup angin bagaikan gelombang laut yang berkilauan jernih. Gemericik air dari lobang pematang sawah jatuh di persawahan /.../ Burung cangak terbang berurutan seperti menunjukkan arah jalan, burung emprit berulangkali lewat membawa sarang ke tengah daun pandan, pohonnya melengkung di saluran air persawahan, membuat tidak tenangnya hati sang pangeran" (Padmasusastra, 1921, P.23).

Selain keindahan alam persawahan, QNKKP juga menceritakan tentang keindahan goa. Dalam data EE.13, SP/P.47-48, diceritakan kondisi goa-goa yang memiliki bentuk yang menarik, lokasinya di lereng gunung, dan mayoritas pernah dihuni oleh manusia. Ini tidak terlepas dari tradisi masyarakat Jawa yang menganggap goa sebagai tempat yang strategis sekaligus sakral untuk melakukan ritual pertapaan. Hal ini juga yang menyebabkan goa menjadi terawat, bahkan ada goa yang ditambah bangunan dan ornamen di dalamnya. Dengan demikian, hubungan antara gambaran estetika alam Jawa dengan peristiwa cerita dapat memberikan pembelajaran bagi kita bahwa, keterjagaan estetika alam dapat memberikan pengaruh positif pada berbagai aspek.

\subsection{Pendidikan Konservasi Lingkungan}

Dalam QNKKP, digambarkan pula tentang beberapa model konservasi lingkungan. Bentuk konservasi yang dalam QNKKP meliputi 3 jenis yang terinci menjadi 5 bentuk penerapan konservasi, yakni

\subsubsection{Konservasi alam}

Bentuk konservasi alam tergambar melalui tata cara menggarap sawah, yang dapat dilihat dalam data EE.15, SPSKA/P.38. Selanjutnya, dalam data EE.16, SPSKA /P.148-150, tergambar pula bentuk konservasi alam berupa pembangunan rumah dengan menggunakan piranti dari unsur alami. Perhatikan kutipan berikut.

"Saudagar muda membuat rumah persegi, pintunya sebanyak enam puluh, di sebelah tengah diberi sela-sela untuk jalan angin menggunakan corong seperti menganganya mulut naga jatuh di usus-usus bisa memberi angin segar pada gedung-gedung di sekeliling rumah, lantainya batu cendani kuning jalan menuju kamar diberi alas babut 
sulaman buatan Kusta. Di tengah rumah diberi sela-sela mengelilingi dibuat taman, batu curi dihias seperti karang, dibentuk gumuk, badan gumuk keluar airnya dari urung-urung besi yang diambil dari gunung. Gumuk karang tersebut diberi tanaman simbar serta lumut yang hidupnya menempel di batu. Keluarnya air ke atas melengkung satelapak tangan, siratannya rata mengenai tanaman yang berada di cekungan gumuk karang. Pemandiannya berbentuk loji persegi berada di pojok memisahketutupan bunga kalak yang sangat tua, saling melilit seperti penutup rumah pemandian" (SKA/147-150)

Narasi tersebut memberikan gambaran bagi kita bahwa, betapa masyarakat Jawa sangat dekat dengan alam. Peristiwa penyatuan alam dalam sebuah bangunan rumah merupakan salah satu cara dari manusia untuk merawat alam, sekaligus bentuk nyata penyatuan diri manusia dengan nilai-nilai alam.

\subsubsection{Konservasi air}

Air merupakan unsur penting yang dapat ditemukan pada hampir semua latar tempat dalam teks novel. Bentuk konservasi air tergambar dalam data EE.17, SP/P.61 dan EE.18,SPSKA/P.39-40, yakni narasi tentang pengelolaan aliran air sungai yang dijadikan untuk mengairi tanaman dan memenuhi kebutuhan air di masjid. Upaya konservasi menandakan bahwa, air adalah salah satu unsur kehidupan yang paling penting dan sacral dalam kehidupan (bandingkan, Widodo, 2013). Representasi air yang begitu penting menuntun berbagai cara manusia untuk tetap merawat dan mengelolanya dengan cara dan budaya pada masa tertentu.

\subsubsection{Konservasi lahan kering}

Kondisi lingkungan dalam QNKKP mayoritas memang didominasi oleh suasana alam yang subur. Namun, di dalam SPSKA, terdapat suatu wilayah yang memliki kondisi lahan yang nampak kurang subur. Ini tergambar dalam EE.19, SPSKA/P.214-217, yakni dalam alur peristiwa tentang pelarian Jaka Erawana, Jaka Bayu, dan prajuritnya dari penjara bajak laut. Dalam upaya untuk mempertahankan hidup, mereka berupaya untuk melakukan pengolahan lahan kering supaya bisa menjadi lahan pangan. Penggarapan lahan dilakukan secara gotong royong, dan dengan norma-norma tradisional. Namun demikian, produk pangan yang dihasilkan tetap memiliki kualitas yang baik.

Konservasi lingkungan memang memerlukan inisiatif individu (Li, 2019). Untuk itu, di sini, kita bisa melihat bagaimana upaya-upaya masyarakat Jawa untuk merawat alam demi masa depan kehidupan bersama. Meskipun niat pengolahan lahan yang dilakukan oleh tokoh adalah untuk produksi bahan pangan, namun pengolahan lahan kering tetap harus dilihat sebagai upaya positif manusia untuk menghijaukan kembali kondisi bumi yang tandus.

\subsection{Pendidikan Altruistik Alam}

Altruistik alam merupakan jasa yang diberikan oleh alam kepada kehidupan di bumi. Kelimpahan sumber daya alam di tanah Jawa memang sangat mendukung keberlangsungan hidup bagi tumbuhan, hewan, dan manusia. Di dalam QNKKP, ditemukan tiga jenis altruisme, yang meliputi altruisme air, goa, dan tanaman, yang terinci sebagai berikut.

\subsubsection{Altruistik air}

Di dalam QNKKP banyak alur yang menampilkan unsur air. Ini tidak lepas dari kenyataan bahwa di Jawa memang secara geografis memiliki kelimpahan sumber daya air. Di 
dalam data EE.20, SP/P.23-24, SP/P.77, sumber air alami bermanfaat untuk mengaliri tanaman. Ketersedian air yang cukup mengakibatkan berbagai tanaman alami maupun tanaman rawatan tampak dapat hidup dengan subur. Data EE.20, SP/59-60 menggambarkan air sebagai sarana transportasi. Selanjutnya, air juga bermanfaat lain, seperti tergambar dalam data EE.21, SPSKA/P.71-72, SKB/P.34-35, yakni tentang penggunaan air untuk kebutuhan hidup manusia. Artinya, air memang memberikan banyak jasa bagi kehidupan di bumi. Untuk itu, diperlukan kepekaan hati dan kepedulian manusia untuk dapat menjaga ketersediaan air demi keberlanjutan hidup.

\subsubsection{Altruistik Goa}

Goa merupakan lokasi alam yang dianggap penting bagi masyarakat Jawa. Sebagian masyarakat tradisional Jawa menggunakan goa sebagai tempat tinggal, seperti dalam EE.22, SP/P.35. Lalu, dalam situasi tertentu, masyarakat juga sering menggunakan goa sebagai tempat bertapa, seperti ternarasikan dalam EE.10, SPSKA/P.71-72; EE.11, SP/P.95-96. Di dalam QNKKP, goa tidak hanya sebagai media praktik kehidupan manusia, tetapi goa dapat pula muncul hanya sebagai narasi pengarang tentang suasana keindahan alam Jawa. Narasi ini dapat terlihat misalnya dalam data EE.23, SPSKA/P.3.

Dalam hal ini, pengarang nampaknya memang memiliki kekaguman yang mendalam pada kondisi goa-goa yang ada di Jawa. Pendeskripsian goa tidak hanya menekankan pada fungsinya, tetapi juga menonjolkan nilai artistiknya. Artinya memang, keindahan bentuk alam Jawa dengan keindahan goa-goa, semua memang memiliki jasa yang tidak ternilai untuk mendukung kehidupan semua makhluk.

\subsubsection{Altruistik tumbuhan}

Kesuburan tanah merupakan bagian yang menjadi keunggulan tanah Jawa. Banyak aneka ragam tanaman dan hutan yang tumbuh subur. Kesuburan hutan Jawa merupakan rumah tinggal yang nyaman bagi binatang dan manusia. Dalam berbagai situasi, manusia akan menggantungkan hidup pada hutan. Untuk masalah ini, kondisi hutan yang sehat dan subur akan sangat membantu memperpanjang umur manusia. Peristiwa tentang kepergian Pangeran Warihkusuma karena diusir dari kerajaan (EE.24, SRT/P.48-49) merupakan merupakan cermin bahwa manusia sangat menggantungkan diri hidupnya pada hutan. Kesehariannya hanya makan dedauan yang muda dan berbagai tumbuhan yang ada. Untuk itu, hutan dengan segala isinya memang sangat nyata memberi altruistik kepada makhluk hidup lain.

Pada peristiwa alur selanjutnya, QNKKP juga menampilkan bentuk pendidikan psikis. Ini tergambar melalui karakter tokoh Pangeran Prabangkara saat mencari kepergian Rara Apyu. Dalam perjalanannya, ia terhenti di sebuah hutan. Ada banyak hal hal yang mempengaruhi psikisnya saat ia berhadapan dengan alam, beserta beberapa binatang yang ia temui. Kutipan berikut menggambarkan hal itu.

"Perjalanannya tidak tentu arahnya /.../ Burung cangak terbang berurutan seperti menunjukkan arah jalan, burung emprit berulangkali lewat membawa sarang ke tengah daun pandan, pohonnya melengkung di saluran air persawahan, membuat tidak tenang hati sang pangeran. Katanya dalam hati: Bagaimana hewan-hewan kecil bisa 
mendapatkan kebahagiaan, kemana-mana selalu bersama pasangannya. Berbeda dengan diriku" (Padmasusastra, 1921, P.23).

Dalam situasi yang kalut, terkadang keindahan alam juga dapat sebagai padanan keindahan seseorang yang kita cintai. Demikian pula, penganalogian keindahan manusia dengan keindahan alam merupakan bentuk penghayatan yang mendalam terhadap nilai-nilai alam. Kemudian, kegelisahan hati Pangeran Prabangkara saat melihat kegembiraan burung-burung merupakan bentuk penghargaan yang sangat tinggi kepada binatang. Artinya, binatang bukanlah makhluk biasa, melainkan binatang adalah makhluk yang layak dihargai, yang mungkin dapat memberi contoh kebahagiaan bagi manusia.

Sejak narasi tersebut berasal dan berkembang, QNKKP banyak memberikan pendidikan bagi pembaca tentang hubungan alam dan manusia dalam perspektif budaya Jawa. Praktik lingkungan yang melekat dalam kehidupan masyarakat Jawa sangat mendukung gerakan prolingkungan untuk jangka panjang. Sistem pengetahuan tradisional Jawa mengajarkan kita tentang pemulihan kesatuan pikiran tentang kesadaran manusia terhadap alam. Kesadaran itu adalah komponen mendasar dari etika lingkungan masyarakat tradisional dan sistem pengetahuan lokal. Dengan demikian, signifikansi narasi ekologi dan etika lingkungan dalam QNKKP memberikan kontribusi terhadap reorientasi beberapa pandangan tentang kultur praktik lingkungan tradisional.

\section{Kesimpulan}

QNKKP merupakan sastra Jawa kontemporer yang menggambarkan tentang kondisi sosiokultural Jawa pada tahun 1901 s.d. 1924. Melalui peristiwa alur, latar, dan karakter tokoh, secara implisit maupun eksplisit merupakan cermin dari cara hidup manusia Jawa yang masih mengutamakan rasa etis terhadap lingkungan dan semua unsur alam. Rasa etis tersebut merupakan tujuan standar hidup ideal yang sesuai dengan nilai-nilai yang berkembang dalam kebudayaan Jawa pada masa QNKKP diciptakan.

Ada upaya transfer nilai pro-lingkungan oleh Ki Padmasusastra kepada pembaca terkait nilai luhur budaya Jawa. Tujuannya adalah agar tercipta kesadaran manusia tentang hubungan yang saling membutuhkan antara manusia dan non-manusia. Dari berbagai situasi peristiwa dan alur cerita, QNKKP menampilkan wawasan pendidikan moral tentang kehidupan masyarakat Jawa tradisional dalam memperlakukan alam. Kesadaran tokoh dapat mendorong manusia untuk membentuk sistem moral ekologis. Kesadaran ini terkait dengan pemahaman masyarakat Jawa tentang alam semesta sebagai entitas yang memiliki nilai, sehingga layak untuk dihargai, dijaga, dan dirawat.

Implikasi penting dari temuan penelitian adalah kesadaran manusia untuk saling menghormati sesama entitas yang ada akan dapat membangun kekuatan yang dapat membimbing manusia agar etis terhadap lingkungannya. Sebuah pemahaman pribadi pengetahuan ekologi adalah dasar dari sikap dan perilaku proenvironmental. Melalui QNKKP, Ki Padmasusastra membangun persepsi etis lingkungan tentang nilai-nilai moral, spiritual, estetika, konservasi, altruistik, psikis, semiotika, kultural, filosofis, dan tradisi herbal. Praktik kehidupan Jawa yang menjunjung harmonisasi, empati, rasa hormat, dan saling membutuhkan terhadap makhluk non-manusia adalah sebuah pembelajaran berharga bagi pembaca sastra. Dengan demikian, QNKKP terlibat dalam ekologi melalui tiga cara, yakni pendidikan lingkungan, intelektual ilmiah, dan praktis. 


\section{Daftar Pustaka}

Asteria, D., Herdiansyah, H., \& Apriana, I. W. A. (2016). Women's Environmental Literacy As Social Capital in Environmental Management for Environmental Security of Urban Area. IOP Conference Series: Earth and Environmental Science, 30(1). https://doi.org/10.1088/1755-1315/30/1/012014

Athanassakis, Y. (2017). Environmental justice in contemporary US narratives. In Environmental Justice in Contemporary US Narratives. https://doi.org/10.4324/9781315712444

Barau, A. S., Stringer, L. C., \& Adamu, A. U. (2016). Environmental ethics and future oriented transformation to sustainability in Sub-Saharan Africa. Journal of Cleaner Production, 135, 1539-1547. https://doi.org/10.1016/j.jclepro.2016.03.053

Beattie, J., \& Liu, T. (2016). Introduction---Environment, Modernization, and Development in East Asia: Perspectives from Environmental History. In Liu, T. \& J. Beattie (Eds.), Environment, Modernization and Development in East Asia: Perspectives from Environmental History (pp. 1-28). https://doi.org/10.1007/978-1-137-57231-8_1

Bishop, K., Reid, A., Andrew Stables, Lencastre, M., Stoer, S., \& Soetaert, R. (2000). Developing Environmental Awareness through Literature and Media Education: Curriculum Development in the Context of Teachers' Practice. Canadian Journal of Environmental Education (CJEE), 5(1), 268-286.

Buell, L. (2005). The Future of Environmental Criticism: Environmental Crisis and Literary Imagination. In Blackwell Publishing. https://doi.org/10.1109/SNPD.2008.112

Charmaz, K. (2011). Grounded Theory pada Abad XXI: Aplikasinya dalam Memajukan Penelitian Keadilan Sosial. In Lincoln, N. K. D. dan Y. S. (Ed.), The Sage Handbook of Qualitative Research (edisi keti, pp. 547-580). Yogyakarta: Pustaka Pelajar.

Cheng, Y., Lou, S., Kuo, S.-H., \& Shih, R.-C. (2013). Investigating elementary school students 'technology acceptance by applying digital game-based learning to environmental education. 29(1), 96-110.

Cortés Capano, G., Toivonen, T., Soutullo, A., \& Di Minin, E. (2019). The emergence of private land conservation in scientific literature: A review. Biological Conservation, 237(July), 191-199. https://doi.org/10.1016/j.biocon.2019.07.010

Dewi, N. (2015). Manusia dan Lingkungan dalam Cerpen Indonesia Kontemporer: Analisis Ekokritik Cerpen Pilihan Kompas. Litera, 14(2), 376-391. Retrieved from https://journal.uny.ac.id/index.php/litera/article/view/7211/6216

Dewi, N. (2018). Ecohumanism in Teaching Poetry for EFL Students in Indonesia. GEMA Online ${ }^{\circledR}$ Journal of Language Studies, 18(2), 168-181. https://doi.org/10.17576/gema2018-1802-12

Dikicigil, Ö., \& Gülersoy, A. E. (2020). Social studies pre-service teachers' awareness of environmental ethics. Elementary Education Online, 19(3), 1579-1591. https://doi.org/10.17051/ilkonline.2020.734482

Endraswara, S. (2016). Memayu Hayuning Bawana. Jakarta: PT Buku Seru.

Gaard, G. (2001). Ecofeminism Women, Animals, Nature. In Temple University Press. Philadelphia.

Garrard, G. (2004). Ecocriticism. USA and Canada: Routledge.

Geertz, C. (1956). Religious Belief and Economic Behavior in a Central Javanese Town: Some Preliminary Considerations. Economic Development and Cultural Change, 4(2), 134-158. 
https://doi.org/10.1086/449708

Glotfelty, C., \& Fromm, H. (1996). The Ecocriticism Reader: Landmarks In Literary Ecology. Athens And London: The University of Georgian PRESS I.

Gough, A. G., \& Robottom, I. (1993). Towards a socially critical environmental education: Water quality studies in a coastal school. Journal of Curriculum Studies, 25(4), 301-316. https://doi.org/10.1080/0022027930250401

Habibi, S. J., \& Karbalaei, S. S. (2015). Incredulity towards global-warming crisis: Ecocriticism in Ian McEwan's Solar. 3L: Language, Linguistics, Literature, 21(1), 91-102. https://doi.org/10.17576/3L-2015-2101-09

Helvaci, S. C., \& Helvaci, İ. (2019). An interdisciplinary environmental education approach: Determining the effects of E-STEM activity on environmental awareness. Universal Journal of Educational Research, 7(2), 337-346. https://doi.org/10.13189/ujer.2019.070205

Holzhauser, K. (2008). Book review. Australasian Emergency Nursing Journal, 11(3), 100100. https://doi.org/10.1016/j.aenj.2008.02.005

Hooti, N., \& Ashrafian, A. (2014). D . H . Lawrence 's St . Mawr: An Ecocritical Study. 3L: The Southeast Asian Journal of English Language Studies, 20(2), 31-42. https://doi.org/http://dx.doi.org/10.17576/3L-2014-2002-03

Kim, W.-C. (2014). Environmental literature and the change of its Canon in Korea. CLCWeb Comparative Literature and Culture, 16(6). https://doi.org/10.7771/1481-4374.2653

Krippendorff, K. (1980). Validity in Content Analysis. Computerstrategien FÃ $\tilde{A}^{1 / 4 r}$ Die Kommunikationsanalyse, 69-112. $\quad$ Retrieved from http://repository.upenn.edu/asc_papers/291

Li, T. (2019). Conservation Science Investigating Pre-1949 Chinese Paper-Based Materials. 10(1), 15-24.

Magnis-Suseno, F. (1984). Etika Jawa. Jakarta: PT Gramedia.

McDonald, S. (2015). Settler Life Writing, Georgic Traditions and Models of Environmental Sustainability. American Review of Canadian Studies, 45(3), 283-298. https://doi.org/10.1080/02722011.2015.1064458

Mobley, C., Vagias, W. M., \& DeWard, S. L. (2009). Exploring additional determinants of environmentally responsible behavior: The influence of environmental literature and environmental attitudes. Environment and Behavior, 42(4), 420-447. https://doi.org/10.1177/0013916508325002

Nichols, A. (2011). Nineteenth-Century Major Lives and Letters. New York: Palgrave Macmillan.

Odinye, I. E. (2018). Social Consciousness: An Analysis of Ifeoma Okoye's The Fourth World. Interdisciplinary Journal of African \& Asian Studies, 1(4), 1-12.

Padmasusastra, K. (1901). Serat Pêthikan Saking Kabar Angin. Surakarta: Yayasan Sastra Lestari.

Padmasusastra, K. (1912). Serat Rangsang Tuban. Surakarta: Yayasan Sastra Lestari.

Padmasusastra, K. (1921). Serat Prabangkara. Surakarta: Yayasan Sastra Lestari.

Padmasusastra, K. (1924). Serat Kôndha Bumi. Surakarta: Yayasan Sastra Lestari.

Pamungkas, O. Y. (2021). Eko-Sufisme Jawa: Representasi Ekokritik dalam Sastra. Yogyakarta: Lintas Nalar. 
Pamungkas, O. Y., Widodo, S. T., Suyitno, \& Endraswara, S. (2018). Ecocriticism: Javanese Cosmology and Ecoethic in Tetralogy Romance by Ki Padmasusastra. Advances in Social Science, Education and Humanities Research, 280(Basa), 480-489. Retrieved from http://creativecommons.org/licenses/by-nc/4.0/

Pamungkas, O. Y., Widodo, S. T., Suyitno, \& Endraswara, S. (2019). Environmental Wisdom: An Observation of Ecocriticism towards the Javanese Cyber Literature in 20th Century. Intenational Journal of Advanced Science and Technology, 28(10), 46-60. Retrieved from http://sersc.org/journals/index.php/IJAST/article/view/981

Pamungkas, O. Y., Widodo, S. T., Suyitno, \& Endraswara, S. (2021). Metaphor as a Strategy of Language Politeness: A Study of the Novel Tetralogy by Ki Padmasusastra. Proceedings of the International Conference on Language Politeness (ICLP 2020), 553(Iclp 2020), 5967. https://doi.org/10.2991/assehr.k.210514.009

Paterson, B. (2006). Ethics for Wildlife Conservation: Overcoming the Human-Nature Dualism. BioScience, 56(2), $144 . \quad$ https://doi.org/10.1641/00063568(2006)056[0144:EFWCOT]2.0.CO;2

Pattaro, C. (2016). Character education: themes and researches. An academic literature review. Italian Journal of Sociology of Education, 8(1), 6-30. https://doi.org/10.14658/pupj-ijse2016-1-2

Quinn, G. (1982). Padmasusastra's Rangsang Tuban: A Javanese Kabatinan Novel. Archipel, 24(Januari), 161-187. https://doi.org/10.3406/arch.1982.1777

Rass, J. J. (2014). Masyarakat dan Kesusastraan di Jawa. Jakarta: Yayasan Pustaka Obor Indonesia.

Ratna, I. N. K. (2010). Metodologi Penelitian Kajian Budaya dan Ilmu Sosial Humaniora pada Umumnya. Yogyakarta: Pustaka Pelajar.

Salisu Barau, A., Stringer, L. C., \& Adamu, A. U. (2016). Environmental ethics and future oriented transformation to sustainability in Sub-Saharan Africa. Journal of Cleaner Production, 135, 1539-1547. https://doi.org/10.1016/j.jclepro.2016.03.053

Strauss, A., \& Corbin, J. (2010). Dasar-Dasar Penelitian Kualitatif. Yogyakarta: Pustaka Pelajar.

Sukmawan, S. (2016). Ekokritik Sastra. Malang: UB Press.

Sunyoto, A. (2012). Atlas Wali Songo. Bandung: Mizan.

Sutopo, H. B. (2002). Metode Penelitian kualitatif. Surakarta: Sebelas Maret University Press.

Suwandi, S., Zainnuri, H., \& Yunus, A. (2019). Ecological literacy values in Indonesian language textbook for senior high school students published by Ministry of Education and Culture. Journal of Physics: Conference Series, 1360(1). https://doi.org/10.1088/17426596/1360/1/012006

Tago, M. Z. (2017). Agama Dan Integrasi Sosial Dalam Pemikiran Clifford Geertz. Kalam, 7(1), 79. https://doi.org/10.24042/klm.v7i1.377

Thathong, K. (2012). A spiritual dimension and environmental education: Buddhism and environmental crisis. 46, 5063-5068. https://doi.org/10.1016/j.sbspro.2012.06.386

Vanderstoep, S. W., \& Johnston, D. D. (2008). Research Methods for Everyday Life (Blending Qualitative and Quantitative Approaches). 400.

Von Mossner, A. W. (2019). Why we care about (Non)fictional places: Empathy, character, and narrative environment. Poetics Today, 40(3), 559-577. https://doi.org/10.1215/033353727558150 
Wibowo, P. A. W. (2015). A Stylistic Study on the Literary Works of Ki Padmasusastra Holistic Critique. 2(5), 139-150.

Widodo, S. T. (2013). Javanese names during the height of the hindu-buddhist kingdoms in java: An ethnolinguistic study. Kemanusiaan, 20(2), 81-89.

Wiyatmi, Liliani, E., \& Budiyanto, D. (2016). Pendidikan Lingkungan melalui Sastra. Yogyakarta: Jurusan Pendidikan Bahasa dan Sastra Indonesia, Fakultas Bahasa dan Seni, Universitas Negeri Yogyakarta.

York, R., \& Rosa, E. A. (2003). Key Challenges to Ecological Modernization Theory: Institutional Efficacy, Case Study Evidence, Units of Analysis, and the Pace of EcoEfficiency. Organization \& Environment, 16(3), 273-288. Retrieved from http://www.jstor.org/stable/26162475

Zhang, J., Liu, L. R., Shi, X. C., Wang, H., \& Huang, G. (2017). Environmental information in modern fiction and ecocriticism. Journal of Environmental Informatics, 30(1), 41-52. https://doi.org/10.3808/jei.201700374 